\title{
UMA LITERATURA TRAJADA DE AZEVICHE
}

\section{Maria Dolores Sosin Rodriguez*}

RESUMO: O presente ensaio busca refletir acerca das determinações que configuram a literatura brasileira e como a produção negra reserva, em seu bojo e fundamentação, questões ignoradas pela teoria da literatura. Pensando em como a figura do cânone oblitera a presença dessa produção, mas também organiza um imaginário, a partir de operadores da representação literária, que produz violência e endossa o processo de necropolítica (MBEMBE, 2018), o ensaio provoca, a partir de algumas leituras de produções que não pertencem ao puro código linguístico, de autoria de Ricardo Aleixo e Dete Lima, o deslocamento sobre as definições sobre do próprio fazer literário.

PALAVRAS-CHAVE: Teoria da literatura; Literatura negra; Ilê Aiyê; Dete Lima; Ricardo Aleixo.

Em consequência de uma imensa má vontade para enxergar o mundo fora da lente monocromática do pensamento, da produção de saberes e dos fazeres, a visão branca, europeia e ocidentalizada das coisas acaba apequenando tudo o que não reconhece e não legitima enquanto suficientemente bom, belo, inteligente e potente. Na vontade de animalizar, animaliza-se (CÉSAIRE, 1978). Na má gestão de suas crises, produz discursos que nos obliteram. No desejo de resolver os seus próprios dilemas, inventados na ficção de suas falsas quimeras, propõe soluções e faz questionamentos que estão muito distantes das

\footnotetext{
* Doutoranda em Teorias e Críticas da Literatura e da Cultura no Programa de Pós-Graduação em Literatura e Cultura da Universidade Federal da Bahia (Ufba).
} 
produções negras que, desde muito antes e sempre, entreveram e produziram desordenamentos, desmobilizações e desarticulações, desde um lugar azeviche, das falácias que gestam as múltiplas formas de busca por um ordenamento centralizador de uma identidade, como por exemplo, o sujeito e a nação.

Dentre as formas centralizadoras da identidade, que buscou e, em certa medida, ainda busca, encontrar uma coerência que opere a partir de uma lógica de identificação, temos a literatura brasileira. Essa literatura, que surge produzindo um desejo de cunhar uma identidade "verdadeiramente" nossa, afastada e autônoma de quem nos colonizou, mas que o faz seguindo a mesma lógica de criação de parâmetros excludentes e a mesma fixação por valores que falseiam e turvam a auto-gestão de povos não-brancos, exercida na produção do cânone enquanto operador de sentido e de valorização.

O cânone, pensando como um problema, como um operador de violências, é estabelecido não apenas excluindo a produção de autoria negra no país, como inventando personagens negras simuladoras de temperamentos indolentes, quando não caricaturas marginalizadas e extremamente sexualizadas que colaram falseamentos nos corpos negros que ratificam o avanço do desprezo e posterior assassinato em massa dessas pessoas, processo ao qual o movimento negro e intelectuais negras e negros vêm chamando de genocida.

É aí que a representação literária exerce o fundamental papel de capitalização de imaginários que reproduzem uma visão unívoca para um grupo múltiplo de pessoas: é dessa forma que a literatura suja as mãos de sangue e segura o revólver do Estado na atuação frente ao quadro desastroso e estarrecedor de gerência social da vida de pessoas negras.

A arte como alimento na formação dessa representação, que já nasce caduca, dadas as limitações da chamada literatura brasileira e dos campos que se dedicam ao seu estudo, é uma arma de guerra. A literatura, por sua vez, também opera violências. E está no bojo, em um lugar prestigiado, dentro da máquina da necropolítica (MBEMBE, 2018).

Assim como a ficção operada pelo Estado, como traz Achille Mbembe, a Literatura também atua de modo a "[...] "civilizar" os modos de matar e atribuir objetivos racionais ao próprio até de matar” (MBEMBE, 2018, p. 33). Assim, a vislumbrarão do cânone, como 
uma das principais vias para esse caminho, também é um caminho de enxergar a metodologia genocida do Estado.

Ainda que, também em alguma medida, fundamentada no enaltecimento dessa nacionalidade brasileira original e distinta, a literatura operou fundamentada em pilhagens, incorporando o pensamento de Henrique Freitas:

Ante o capitalismo etnicorracial que saqueou os corpos indígenas e negros no Brasil-Colônia, e ante também a colonialidade do poder-saber ainda em curso, que instituiu as pilhagens teóricas e epistêmicas dessa mesma diferença como modus operandi do soerguimento da literatura nacional, é preciso força plástica para nos tornar, nietzscheanamente, aquilo que somos como potência em devir de uma expressão artística brasileira, já que ainda não nos permitimos à radicalidade das experiências éticas e estéticas que as gnoses indígena e afro-brasileira (africana e negro-brasileira) nos oferecem. Vale salientar que, exatamente por causa do flerte com esses saberes, a literatura brasileira ganhou no decurso da história uma projeção internacional, ao mesmo tempo em que o epistemicídio, aliado ao genocídio, encarregou-se de tentar apagar essa alteridade como corpo físico e gnosiológico. (FREITAS, 2016, p. 38 - 39).

Pensando em nos tornarmos aquilo que somos, como Henrique Freitas descreve, a partir do gesto de Nietzsche, esse ensaio que escrevo propõe estender o pensamento sobre a literatura dos tecidos na construção de um devir negro. Mas, mais do que pensar na desmobilização do cânone, na remissão dos pecados do Ocidente, na ressurreição de uma vontade de adequação ao literário e ao discurso nacionalista e na comunhão com às produções brancas, a partir de uma entrada nos seus campos disciplinares, demonstrando que somos capazes, considero mais frutífero operar desde outro lugar - ainda que para fazê-lo seja necessário pinçar o pensamento e a produção de um(a) ou outro(a) teórico(a) que não esteja interessado(a) nas produções negras e que não seja negro ou negra.

Nesse movimento, por exemplo, é interessante pensar no texto "Cânon", de Roberto Reis, quando ele diz: “A constituição de um sistema literário pouco a pouco engendra uma norma estética e regras de controle, capazes de conservar a identidade destes intelectuais, ao mesmo tempo que rebaixa e recalca aquelas manifestações literárias que infringem 
o sistema em gestação” (REIS, 1992, p. 72). O que estamos aqui pensando é como a literatura negra acontece em devir, assim como a arte negra, no geral, na desarticulação do próprio campo literário e das próprias premissas da arte que vêm sendo problematizadas pela chamada crítica contemporânea.

A problematização, por exemplo, da literatura enquanto código puro e a introdução de outros códigos dentro do seu campo conceitual, a multiplicação de linguagens artísticas e de suportes, as plurifacetas que adentram o literário e o pensamento que se desdobra para o entendimento dos trânsitos na arte: tudo isso já era um pressuposto das artes negras, tendo em vista a própria conceitualização das artes africanas que permanecem com grande impacto e vivacidade nos corpos negros em diáspora, posto que guardamos segredos e memórias em nosso corpo. O símbolo esteta de uma arte feita apenas para a apreciação diletante é um traço de sustentação do mundo Ocidental, mas não se sustenta nas artes africanas:

Por outro lado, falar em "arte" para os objetos de escultura negra, bem como para as máscaras ritualísticas, requer alguns esclarecimentos relativizadores. Quando pensarmos mais rigorosamente nas estatuetas africanas, nas máscaras e nos objetos de cerâmica, nas peças de indumentária mágica e nos adornos, e em tantos outros produtos daquilo que, por convenção, denominamos arte negra, deveremos ter sempre em mente que, nas suas culturas de origem, todos estes objetos são "objetos de ação", e não para serem contemplados ou consumidos como obras de arte à maneira ocidental (BARROS, 2011, p. 39)

A literatura negra, por sua vez, enquanto artefato artístico, também é um objeto de ação. Ao mesmo tempo em que questiono o campo literário enquanto uma produção ocidental cheia de vícios, também penso, fazendo uma grande ressalva, que muitas das nossas produções podem ser classificadas enquanto literárias. Pois, muito embora elas possam estar na classificação do literário, isso não confere a elas nenhum valor que possa ser acrescido por uma entrada meramente permissiva, benevolente ou legitimadora - recursos com que a branquitude vem operando o tratamento destinado a nós dentro dos seus sistemas. 
Sempre que penso na cultura negra, no geral, e na arte negra, no particular, opero a ideia, atravessada pela dupla consciência de Du Bois, da teoria dos conjuntos matemáticos: pertence e não pertence, contém, está contido. A literatura negra pertence ao conjunto da literatura, mas não está contida nele. Sua forma se estende muito além da definição ocidental que é replicada de maneira hegemônica. As formas artísticas negras propõem a multiplicidade como base. O trânsito como método, a confluência dos suportes como ação corriqueira.

Outra dimensão mobilizadora importante para a literatura que as formas negras operam está no entendimento acerca da autoria. O inicial escamoteamento ilusório de uma individuação, o surgimento do autor, o seu desaparecimento e o seu ressurgimento. Denise Carrascosa, em um texto intitulado "Pós-Colonialidade, Pós-Escravismo, Bioficção e Con(tra)temporaneidade" (2014), nos localiza e nos convida a pensar a respeito de algumas categoriais conceituais que nos estão sendo colocadas no que ela chama de "tempos ditos pós-modernos” (CARRASCOSA, 2014, p. 105).

Para ela, existe uma discursividade operando exacerbadamente ao redor de mecanismos que tangenciam um descentramento do sujeito. A pergunta que eu considero central e que nos move, fazendo rachar o terreno por vezes enredado que a tradição de uma teoria da literatura propõe, é a seguinte:

Diante dessa premissa, devemos perguntar quanto de um europeísmo universalista ainda fica como traço residual nessas categorias teóricas nomeadas a partir do desejo de suspensão de fronteiras entre realidade e ficção, da vontade de dissolução da unidade discursiva do indivíduo? (CARRASCOSA, 2014, p. 107).

Quando voltamos a algumas ruínas e nos remetemos às teorias de Staiger e Rosenfeld, por exemplo, observamos que, a partir de suas conceituações, chegaremos a um sujeito lírico que é a expressão de uma pura interioridade. Ora, essa pura interioridade, confundida com o senso moral de uma verdade, também coloca esse sujeito como portavoz de uma universalidade que reafirma um padrão etnocêntrico. 
O que Denise Carrascosa diz aqui é que esse mesmo universalismo que moveu o entendimento de um autor de poesia descolado da história, pairando sobre valores ditos universais, e também a produção de um sujeito deslocado de uma construção baseada em demandas sociais, culturais e atravessado por relações de poder, reflete um universalismo que move as teorias que falam da dissolução sobre a unidade discursiva do indivíduo.

Assim, o sentimento de desacomodar essa voz que se apresentava como uma voz autoritária, que anunciava uma verdade restritamente localizada, estava ligado a uma construção que buscava também um questionamento acerca do cânone e do que ele trazia consigo enquanto expressão ideológica de um grupo hegemônico. Ainda nesse sentido, podemos enxergar o sujeito como inacabado em sua própria definição. Leonor Arfuch diz em Antibiografias? Novas Experiências nos Limites (2012):

\begin{abstract}
A concepção de sujeito da psicanálise, sobretudo em sua vertente lacaniana, foi funcional em nosso empenho: um sujeito constitutivamente incompleto, modelado pela linguagem, cuja dimensão existencial e dialógica, aberto a (e construído por) um Outro: um outro que pode ser tanto o você da interlocução quanto a própria condição de ser outro da linguagem e a ideia de um Outro como diferença radical (ARFUCH, 2012, p. 16).
\end{abstract}

Assim, se estabelece um novo jogo, que ela mesma acrescenta dizendo, no capítulo “O Mito do Eu: Pluralidade e Disjunção” do livro O Espaço Biográfico (2010), que o que interessa, então, "não é uma política da suspeita sobre a veracidade ou a autenticidade dessa voz, mas antes a aceitação do descentramento constitutivo do sujeito enunciador". O que percebemos é que o descentramento proposto por Leonor Arfuch encontra fundamentação na ideia de que o sujeito não parte de uma unidade discursiva, pois não haveria unidade.

Nesse sentido, Carrascosa está apontando para a direção das subjetividades de indivíduos marginalizados em um cenário "pós-colonial". Ela diz respeito, também, aos agenciamentos coletivos de enunciação. Não é que ela ignore o fato de que os sujeitos subalternizados, em perspectiva hegemônica, não possam possuir uma pluralidade discursiva. Ela está, nitidamente, falando sobre a necessidade de formação ainda das subjetividades de indivíduos que não obtiveram, ainda, sua humanidade totalmente reconhecida. 
Ela nos mobiliza:

A noção de "espaço biográfico" (Arfuch, 2010), revisora do conceito de "pacto autobiográfico" (Lejeune, 2008), ambas as funções teóricas derivantes das premissas que orbitam em torno dos conceitos ligados ao "bioficcional" pertencem ao território epistemologicamente operacionalizado pelo pensamento pós-estrutural europeu, notadamente no que concerne à questão da produção subjetiva contemporânea (CARRASCOSA, 2014, p 108).

Então, essa vontade de descentramento que tem ressoado nos estudos de produção de subjetividades na contemporaneidade, seria uma vontade de ordem pós-estrutural europeia.

Fotografia 01 - poemanto, de Ricardo Aleixo

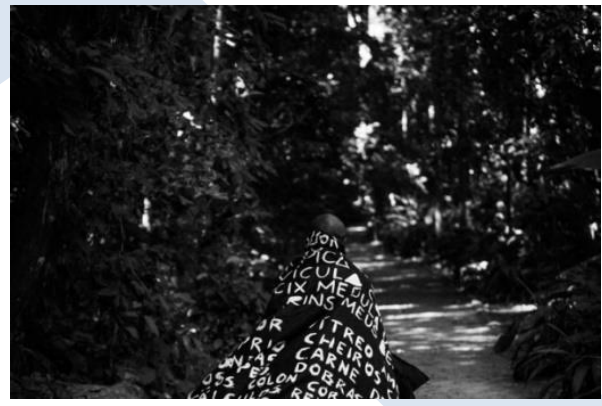

Fonte: Complemento Pernambuco - Fabio Seixo

Fotografia 02 - poemanto, de Ricardo Aleixo

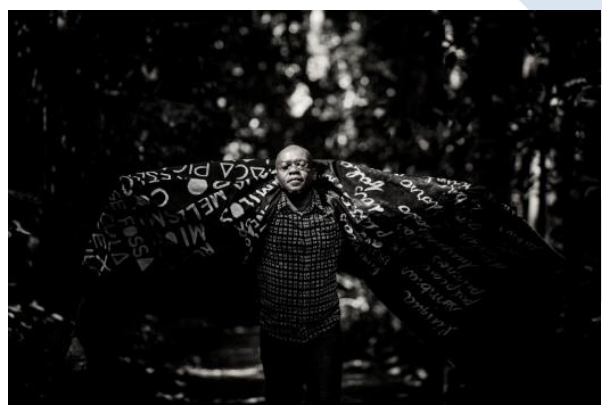

Fonte: Complemento Pernambuco - Fabio Seixo 
É sabido que os tecidos africanos, mais do que ornarem os corpos e produzirem prazer e bem-estar pros sentidos, são escrituras e narram histórias negras. Quero pensar, aqui, sobre a literatura de Dete Lima e de Ricardo Aleixo, artistas negrxs brasileirxs.

Além do papel narrativo que os tecidos constroem e do seu importante lugar de transmissão de histórias, pensemos sobre o que assinala Veruska Barreiros Gonçalves: "Quando nos referimos à moda como linguagem, não é no sentido de transmissão de mensagens, mas no sentido de a moda evocar sinais de pertencimento, na maioria das vezes, utilizando o próprio corpo. Para entender a moda como linguagem é necessário ir além desse conceito de transmissão de mensagem" (GONÇALVES, 2017, p. 30). Dessa forma, o tecido performa uma história, mas também performa o pertencimento.

Construído como um objeto artístico, ele serve como suporte para a escrita de Ricardo Aleixo em sua performance poemanto. Em uma produção que circula ao redor do que o manto oculta e do que ele mostra, torna-se, ele mesmo, o próprio corpo do poeta no momento em que a performance acontece. Vestido de palavras, as palavras também se articulam a partir da movimentação que Aleixo faz. A cada ação, as palavras se organizam de forma diferente. Aqui, cabem algumas perguntas: Quem escreve sobre o quê? É o corpo do poeta que escreve ou é o próprio manto que produz significado sobre o corpo do poeta?

A partir de uma reflexão sobre a cena histórica, política e cultural do Brasil e após observar os vestígios que o colonialismo delegou para a formação das características que estão incorporadas na identidade nacional e nas concepções constituintes da crítica literária e dos estudos culturais, percebemos como é ainda difícil o reconhecimento de outros fazeres como parte importante desses registros e estudos sobre esferas de experiências que fogem à hegemonia, além dos obstáculos que outras narrativas encontram para sua inserção e legitimação dentro do campo dos estudos de teorias e representações literárias e culturais.

Nesse sentido, Grada Kilomba, ao remeter-se a uma máscara utilizada como objeto de silenciamento e tortura, afirma que "a máscara representa o colonialismo como um todo. Ela simboliza políticas sádicas de conquista e dominação e seus regimes brutais de silenci- 
amento dos(as) chamados(as) 'Outros(as)': Quem pode falar? O que acontece quando falamos? E sobre o que podemos falar?” (KILOMBA, 2016, p. 172). Assim, no campo simbólico, novos modos de narrar a história e de produzir literatura seguem sendo silenciados porque as produções de determinados grupos continuam sendo vistas como aquém ou fora do padrão e das exigências que estabelecem o que pode e o que não pode ser chamado de literatura.

O Ilê Aiyê vem promovendo diversos deslocamentos quando traz, há mais de quarenta anos, a figura do negro brasileiro em outros níveis de vínculo consigo mesmo e com as esferas da cultura e da história da sociedade brasileira. Na literatura, o cânone ocupa um lugar que também foi legitimado por relações de poder e, no caso brasileiro, especificamente, fortemente marcado por ranços colonialistas, privilegiando vozes e autorizando que determinadas narrativas tivessem lugar de destaque. No entanto, em um movimento quase sempre insurgente, outras vozes sempre se arquitetaram fora dessa cena.

Assim, fica evidenciado que as narrativas construídas pelo povo negro no Brasil, a partir de muitas de suas produções, trazem uma nova maneira de escrever a história oficial do país, as artes e a própria ideia acerca da humanidade que, nos ciclos oficiais e hegemônicos, parecem contemplar apenas a humanidade como um atributo da branquitude. Por isso, o entendimento do Ilê Aiyê como um local de produção dessa via de construção de uma outra narrativa passa pela ideia de que ele contempla novas estruturas e atualiza o conceito acerca da ideia de literatura.

$\mathrm{Na}$ figura de Dete Lima, intelectual que opera escritas e epistemologias a partir dos tecidos, uma das fundadoras desse primeiro bloco afro, pensemos as formas de produção e de desorganização que elas produzem quando pensadas dentro do campo literário. 
Fotografia 03: Dete Lima e Gisele Soares

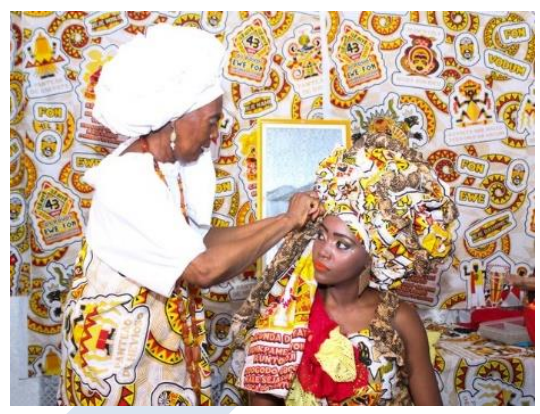

Fonte: G1 Globo (2017)

Essas formas de criação e produção de conhecimento, a partir da arte, das expressões culturais, reorientam e reencenam a história e a produção de narrativas. Por isso que, aqui, esse modo de produção é chamado de escrita com o corpo.

O que se observa, desse modo, é que nos inserimos aqui no que Homi Bhabha disse ser teoricamente inovador e politicamente crucial: "a necessidade de passar além das narrativas de subjetividades originárias e iniciais e de focalizar aqueles momentos ou processos que são produzidos na articulação de diferentes culturas" (BHABHA, 1998, p. 20) ou, ainda, o que ele diz mais adiante quando fala que:

A significação mais ampla da condição pós-moderna reside na consciência de que os "limites" epistemológicos daquelas ideias etnocêntricas são também as fronteiras enunciativas de uma gama de outras vozes e histórias dissonantes, até dissidentes [...] Cada vez mais, as culturas "nacionais" estão sendo produzidas a partir da perspectiva de minorias destituídas" (BHABHA, 1998, p. 24-25).

É a partir dessa ideia de uma narrativa construída a partir de uma entidade marcadamente negra, que se impões a partir da estética dos quilombos e que escreve a história a partir das manifestações artísticas e culturais que opera, que essa pesquisa se debruça e se interessa. A partir de um contraponto e do estabelecimento de uma nova produção que possui ressonâncias estéticas, intelectuais e literárias, o Ilê Aiyê vêm reescrevendo a história 
do Brasil há décadas e, assim, remontando os lugares estabelecidos pelas totalizações e apagamentos promovidos pelo Estado e por outros âmbitos de poder, a exemplo da arte.

Pensando a partir dessa perspectiva e do que Muniz Sodré coloca quando diz que "o problema de reelaboração do estatuto cultural do sujeito afro-brasileiro é, antes de mais nada, ético" (SODRÉ, 1999, p. 200), nada mais coerente, a partir do que foi exposto, do que pensar como o Ilê Aiyê reestabelece, inova e subverte conceitos modulados por instâncias hegemônicas que seguem legando a produção negra como algo fora das questões importantes para serem pensadas no que tange os estudos da cultura e da literatura.

\title{
LITERATURE IN JET STONE COSTUME
}

\begin{abstract}
The present essay seeks to reflect on the determinations that shape the Brazilian literature and how the black production reserves, in its bulge and foundation, issues ignored by the literature theory. Thinking about how the canon figure obliterates the presence of this production, but also organizes an imaginary, based on operators of literary representation, which produces violence and endorses the process of necropoly (MBEMBE, 2018). of some readings of productions that do not belong to the pure linguistic code, authored by Ricardo Aleixo and Dete Lima, the displacement on the definitions about the literary doing itself.
\end{abstract}

KEYWORDS: Literary theory; Black literature; Ilê Aiyê; Dete Lima; Ricardo Aleixo.

\section{REFERÊNCIAS}

ARFUCH, Leonor. Antibiografias? Novas experiências nos limites. In: SOUZA, Eneida Maria de; TOLENTINO, Eliana da Conceição; MARTINS, Anderson Bastos (Org.). O futuro do presente: arquivo, gênero e discurso. Belo Horizonte: Editora UFMG, 2012. p. 13-27.

ARFUCH, Leonor. O espaço biográfico: dilemas da subjetividade contemporânea. Rio de Janeiro: EdUERJ, 2010.

BARROS, José D'Assunção. As influências da arte africana na arte moderna. Revista AfroAsia 44, 37-95, 2011

BHABHA, Homi. Introdução. O local da cultura. Belo Horizonte: UFMG, 1998.

CÉSAIRE, Aimé. Discurso sobre o colonialismo. Primeira. [S.l.]: Sá da Costa Editora, 1978. Tradução de Noémia de Sousa. 
CARRASCOSA, Denise. Pós-colonialidade, pós-escravismo, bioficção e con(tra)temporaneidade. Estudos de literatura brasileira contemporânea, n. 44, p. 105-124, jul./dez. 2014.

FREITAS, Henrique. O Arco e a Arkhé: Ensaios sobre Literatura e Cultura. Salvador: Ogum's Toques Negros, 2016.

GONÇALVES, Veruska Barreiros. Moda afro-baiana: comunicação e identidade através da estética afro. 2008. 125 f. Dissertação (Mestrado em Estudos Étnicos e Africanos) - Faculdade de Filosofia e Ciências Humanas, Universidade Federal da Bahia, Salvador, 2008.

KILOMBA, Grada. A Máscara. Cadernos de Literatura em Tradução, n. 16, p. 171-180. Tradução de Jessica Oliveira de Jesus.

REIS, Roberto. Cânon. In: JOBIM, José Luís. Palavras da crítica. Rio de Janeiro: Imago, 1992. p. 65-92.

SODRÉ, Muniz. A Raça e o Segredo. In: Claros e Escuros. Petrópolis: Vozes, 1999.

Recebido em: 17/09/2018.

Aprovado em: $21 / 12 / 2018$. 